\title{
Membrane NADPH Oxidase Activity and Cell Size in Bovine Neonatal and Adult Neutrophils
}

\author{
MONIQUE DORE, DAVID O. SLAUSON, ${ }^{1}$ AND NANCY R. NEILSEN \\ Inflammation Research Laboratory, Department of Pathology, College of Veterinary Medicine, Cornell \\ University, Ithaca, New York 14853
}

\begin{abstract}
Neutrophils (PMN) from newborn calves generate significantly less superoxide anion $\left(\mathrm{O}_{2}^{-}\right)$than do their adult counterparts after stimulation with direct protein kinase $C$ agonists. To better understand this observation, we compared the activity and kinetics of NADPH oxidase in membrane fractions from phorbol 12-myristate 13-acetate-stimulated adult and newborn PMN. After phorbol 12-myristate 13-acetate stimulation, PMN were sonicated and the membranes assayed for $\mathrm{O}_{2}^{-}$production with increasing concentrations of $\mathrm{NADPH} . \mathrm{O}_{2}^{-}$production was calculated 1 and $2 \mathrm{~min}$ after the beginning of the reaction. At all concentrations of NADPH used, there was no difference $(\mathrm{p}>0.05)$ in $\mathrm{O}_{2}^{-}$production between adult $(n=8)$ and newborn $(n=9)$ PMN membrane preparations. Enzyme kinetics calculations revealed no differences $(p>$ 0.05 ) between age groups in $\mathrm{Km}$ and $V \mathrm{max}$ or in the velocity of the reactions. Determination of the protein content in the membrane pellet, however, showed that adult PMN yielded significantly $(p<0.01)$ higher amounts of protein $(2.82 \pm 0.14 \mathrm{mg} / \mathrm{mL})$ than did newborn PMN $(1.78$ $\pm 0.07 \mathrm{mg} / \mathrm{mL}$ ). This difference could be partly attributed to cell size; flow cytometric analysis showed that newborn PMN had a significantly $(p<0.01)$ smaller diameter $(10.94 \pm 0.07 \mu \mathrm{m})$ than did adult PMN $(11.65 \pm 0.06 \mu \mathrm{m})$, and calculated cell volume and surface area were also both significantly less $(p<0.01)$ in newborn PMN. These data collectively showed that the observed difference in $\mathrm{O}_{2}^{-}$ production between newborn and adult bovine PMN stimulated with protein kinase $C$ agonists was not due to a difference in the activity or the kinetics of the enzyme NADPH oxidase, and that PMN from newborn calves had a significantly smaller diameter, volume, and surface area than did adult PMN. These size differences could play a role in the $\mathrm{O}_{2}{ }^{-}$generating deficit of newborn bovine PMN. (Pediatr Res 28: 327-331, 1990)
\end{abstract}

$\mathrm{O}_{2}^{-}$, superoxide anion

PMA, phorbol 12-myristate 13-acetate

PKC, protein kinase $C$

HBSS, Hanks balanced salt solution

PMN, polymorphonuclear neutrophil

Received March 28, 1990; accepted May 31, 1990.

Correspondence and reprint requests: Dr. D. O. Slauson, Department of Pathobiology, College of Veterinary Medicine, University of Tennessee, P.O. Box 1071, Knoxville, TN 37901

Supported by a U.S.D.A. Section 1433 Program Grant and a Competitive Research Grant (D.O.S.) and by a fellowship from the Medical Research Council of Canada (M.D.).

' Present address: Department of Pathobiology, College of Veterinary Medicine, University of Tennessee, P.O. Box 1071, Knoxville, TN 37901.
Immaturity or abnormality of both humoral and cellular systems of defense is believed to play a significant role in the increased incidence of life-threatening bacterial infections in newborn humans and animals (1-3). Among the professional phagocytes involved in cellular defense, PMN are especially important in bacterial infections, and their various defensive functions must be well coordinated to effectively combat infection. Any impairment of the functional capabilities of PMN from neonates could potentially reduce their protective effects.

Several disparities in the functional state of PMN isolated from cord blood of neonates have been documented in man, including differences in their motility $(4,5)$, chemotactic response $(6)$, adherence $(7,8)$, aggregation (9), and bactericidal activity (10). One of the most important features of PMN microbicidal activity is the ability to generate toxic oxygen radicals such as $\mathrm{O}_{2}^{-}, \mathrm{H}_{2} \mathrm{O}_{2}$, and $\mathrm{OH}$ through the metabolic process known as "the respiratory burst." Conflicting reports exist on the state of activity of the respiratory burst of PMN from human newborns, and data documenting either comparable $(10,11)$, diminished (12), or increased $(13,14)$ production of $\mathrm{O}_{2}^{-}$by newborn PMN stimulated with various agonists have been reported.

Elevated morbidity and mortality resulting from opportunistic bacterial infections are also common in newborn calves $(15,16)$ and, as in man, are likely due to immaturity of immunologic and cellular mechanisms of defense. As for human neonatal PMN, studies of newborn calf PMN have revealed functional abnormalities such as enhanced shape change responses to complement fragments (17), and decreased ability to generate $\mathrm{O}_{2}{ }^{-}$in response to direct PKC agonists (17-19).

The enzymatic complex responsible for the generation of free radicals in PMN is an oxidase that transfers electrons from intracellular NADPH to reduce molecular oxygen to produce the first oxidant, $\mathrm{O}_{2}{ }^{-}$. The enzyme, NADPH oxidase, is located in the plasma membrane and is believed to consist of at least three components, a low potential cytochrome, a flavoprotein, and possibly a quinone (20). To investigate the biochemical basis for the difference in respiratory burst activity in human neonates, Ambruso et al. (21) studied the activity of this enzyme in membrane-rich fractions of PMA-stimulated PMN and reported increased production of $\mathrm{O}_{2}^{-}$by newborn PMN and differences in both the apparent $\mathrm{Km}$ and the $\mathrm{V}_{\max }$ of the reaction between adult and newborn PMN

$\mathrm{O}_{2}^{-}$generation also appears to depend on cell size. It has recently been shown, for example, that human peripheral blood could be separated into at least six volume-dependent fractions, and that volume was positively correlated with $\mathrm{O}_{2}{ }^{-}$release when PMN were stimulated with either the chemotactic peptide formyl-methionyl-leucyl-phenylalanine or the phorbol ester tumor promoter PMA $(22,23)$.

To better understand the diminished production of $\mathrm{O}_{2}{ }^{-}$observed in PMN from newborn calves stimulated with PKC agonists, the activity and kinetics of the plasma membrane 
enzyme NADPH oxidase were compared between PMA-stimulated bovine newborn and adult PMN. In addition, diameter, volume, and surface area of neonatal and adult PMN were determined to see if the disparity in $\mathrm{O}_{2}{ }^{-}$production could be due to differences in cell size.

\section{MATERIALS AND METHODS}

Animals. Two age groups of clinically normal Holstein-Friesian cattle were used, including adult females ( $>2$ y of age) and newborn calves $(<24$-h-old) of either sex. All adult animals were fed a normal diet, given water ad libitum, and received no drugs during the course of the study. Newborn calves were allowed to nurse.

Hematology. Total and differential leukocyte counts and hematocrit values were obtained for each sample as an indicator of the normalcy of the samples using routine hematologic methods as described $(17,18)$. Only samples within established normal limits were used in these studies.

Neutrophil isolation. Blood $(60-120 \mathrm{~mL})$ was collected by jugular venipuncture using acid citrate dextrose as the anticoagulant (1:10, acid citrate dextrose:blood ratio). PMN were isolated by differential centrifugation combined with hypotonic lysis of the red blood cells as previously described $(17,18)$. Briefly, blood was centrifuged $(730 \times g$ for $15 \mathrm{~min}$ ) and the plasma, buffy coat, and the top half of the red cell layer were aspirated and discarded. Red blood cells were lysed by addition of $20 \mathrm{~mL}$ of cold, sterile, distilled water and isotonicity restored with $10 \mathrm{~mL}$ of cold sterile saline $(2.7 \% \mathrm{NaCl})$. PMN were pelleted by centrifugation $(200$ $\times g$ for $10 \mathrm{~min}$ ) and washed twice with cold HBSS without $\mathrm{Ca}^{2+}$ and $\mathrm{Mg}^{2+}$. The final cell suspension was adjusted to a concentration of $4 \times 10^{7}$ cells/mL in HBSS containing $\mathrm{Ca}^{2+}$ and $\mathrm{Mg}^{2+}$ for the NADPH oxidase experiments and to a concentration of $1 \times$ $10^{6}$ cells $/ \mathrm{mL}$ for the cell size experiments. Purity of the cell suspension was verified by Wright-Giemsa stained cytocentrifuge preparations and cell viability was determined by trypan blue exclusion.

Neutrophil stimulation. PMN isolated from adult animals ( $n$ $=8$ ) and newborn calves $(n=9)$ were preincubated at $37^{\circ} \mathrm{C}$ for $5 \mathrm{~min}$ and then stimulated with prewarmed PMA $(0.8 \mu \mathrm{g} / \mathrm{mL})$ for $5 \mathrm{~min}$. The reaction was stopped by placing the tube on ice for $10 \mathrm{~min}$, and the cells were subsequently pelleted by centrifugation $(500 \times \mathrm{g}, 7 \mathrm{~min})$ at $4^{\circ} \mathrm{C}$. PMN were resuspended to a concentration of $4 \times 10^{7}$ cells $/ \mathrm{mL}$ in $5 \mathrm{~mL}$ of cold $0.34 \mathrm{M}$ sucrose.

Membrane preparation. PMN membranes were prepared according to the method previously described by Tauber (24). Briefly, cells suspended in cold $0.34 \mathrm{M}$ sucrose were disrupted on ice with a sonicator (Braun-sonic 1510, Braun Melsungen, Melsungen, FRG) by two cycles of $15 \mathrm{~s}$ at $60 \mathrm{~W}$ and one cycle of $10 \mathrm{~s}$ at $40 \mathrm{~W}$. The degree of cell disruption was monitored after each cycle and was usually greater than $95 \%$ after the last cycle. Unbroken cells and nuclei were pelleted by centrifugation $(260 \times g, 10 \mathrm{~min})$ and the supernatant containing the membranes was subsequently centrifuged at $27000 \times g$ for $20 \mathrm{~min}$ in a $\mathrm{J} 2$ 21 centrifuge (Beckman Instruments, Inc., Fullerton, CA) at $4^{\circ} \mathrm{C}$. The resulting membrane pellet was resuspended in $2 \mathrm{~mL}$ of cold $0.34 \mathrm{M}$ sucrose, gently homogenized with a Teflon pestle, and the protein content of the final preparation was determined by the Coomassie Brilliant Blue technique using BSA as the protein standard. To confirm the presence of plasma membrane in the preparations, the activity of the plasma membrane marker alkaline phosphatase was measured by following the hydrolysis of $p$-nitrophenyl phosphate by the enzyme, yielding $p$-nitrophenol and inorganic phosphate (Sigma Chemical Co., St. Louis, MO). High levels of alkaline phosphatase (>167 IU) were found in the membrane preparations tested.

NADPH oxidase assay. $\mathrm{O}_{2}^{-}$production was routinely measured at room temperature by following the SOD-inhibitable reduction of ferricytochrome $\mathrm{C}$ in a double-beam recording spectrophotometer (ACTA MIV, Beckman Instruments, Inc.) at $550 \mathrm{~nm}$ wavelength. The sample cuvette contained the membrane-rich fraction $(140-320 \mu \mathrm{g})$, ferricytochrome C $(1.5 \mathrm{mg}$ / $\mathrm{mL})$, NADPH $(0-250 \mu \mathrm{M})$, and $0.13 \mathrm{M}$ potassium phosphate buffer in a total volume of $1 \mathrm{~mL}$. The reference cuvette contained the same reagents plus SOD $(0.4 \mathrm{mg} / \mathrm{mL}) . \mathrm{O}_{2}{ }^{-}$production was determined 1 and 2 min after starting the reaction by adding $\mathrm{NADPH}$, and was calculated using an extinction coefficient for ferricytochrome $\mathrm{C}$ of $21 \mathrm{mM}^{-1} \mathrm{~cm}^{-1}$. Results were expressed as nmoles $\mathrm{O}_{2}^{-} / \mathrm{min} / \mathrm{mg}$ protein. $\mathrm{Km}$ and $\mathrm{V}_{\max }$ of the reaction were calculated using the computer program (Plot Data Analysis and Graphing Program, New Unit, Inc., Ithaca, NY).

Neutrophil size determination. PMN from adults $(n=12)$ and newborns $(n=12)$ were suspended to a concentration of $1 \times 10^{6}$ cells/mL in HBSS containing $\mathrm{Ca}^{2+}$ and $\mathrm{Mg}^{2+}$, kept in siliconized tubes to prevent cell activation, and analyzed shortly after isolation. PMN from at least one adult and one newborn were analyzed on the same day. Cell diameter was determined by measuring the log forward angle light scattered of $>10000$ PMN with an EPICS Profile Analyzer flow cytometer (Coulter Corp., Hialeah, FL). The flow cytometer was calibrated before each experiment with polystyrene beads of known diameter $(5.1,9.79$, 14.16, and 19.64 $\mu \mathrm{m}$, EPICS Division of Coulter Corp.). For each experiment, diameter was determined on fresh samples and on samples after fixation in $2.5 \%$ glutaraldehyde. In addition, fixed samples from all experiments were saved, stored at $4^{\circ} \mathrm{C}$, and reanalyzed on the same day. Cell volume and surface area were also calculated using the following formulas: $V=\pi D^{3} / 6$ and $\mathrm{S}_{\mathrm{a}}=\mathrm{ID}^{2}$, where $\mathrm{V}=$ volume, $\mathrm{D}=$ diameter, and $\mathrm{S}_{\mathrm{a}}=$ surface area.

Statistical analysis. All results are expressed as mean \pm SEM. Data from two groups were compared using a $t$ test. In cases of more than two groups, one-way analysis of variance and Duncan's multiple range tests were used to determine which means were significantly different.

Reagents. PMA, SOD, ferricytochrome C, NADPH type III, BSA, and potassium phosphate dibasic were purchased from Sigma Chemical Co. Potassium phosphate monobasic and sucrose were obtained from Fisher Scientific Co., Fair Lawn, NJ. Coomassie Brilliant Blue used for the protein determination was purchased from Bio-Rad, Richmond, CA. PMA was dissolved in DMSO, aliquoted, and kept frozen at $-70^{\circ} \mathrm{C}$. SOD and ferricytochrome $\mathrm{C}$ were prepared in sterile distilled water, aliquoted, and kept frozen at $-20^{\circ} \mathrm{C}$. Lyophilized NADPH was kept in the dark at $-20^{\circ} \mathrm{C}$ and was prepared daily in sterile distilled water immediately before use.

\section{RESULTS}

Hematology. Newborn calves had an elevated total white cell count compared with adult cows $(14483 \pm 1209$ versus 10082 \pm 573 cells $/ \mu \mathrm{L}$, respectively) and a higher percentage of neutrophils (PMN) ( $78 \pm 2$ versus $38 \pm 3 \%$, respectively), as previously reported (25). This difference is classically attributed to a release of corticosteroids by the calf during parturition $(26,27)$. This phenomenon was reflected in the higher percentage of PMN in the final suspensions from newborn calves $(99 \pm 0 \%)$ as compared with those of adult cows $(93 \pm 1 \%)$. Viability assessed by trypan blue exclusion was always high $(>98 \%)$.

Protein determination. The results in Figure 1 show the amount of protein in the membrane preparations of both newborn and adult PMN. Membrane preparations resulting from the lysis of $2 \times 10^{8}$ PMN from newborn calves consistently yielded a significantly reduced amount of protein $(1.78 \pm 0.07$ $\mathrm{mg} / \mathrm{mL}, p<0.01$ ) when compared with those from adult animals $(2.82 \pm 0.14 \mathrm{mg} / \mathrm{mL})$.

Activity of NADPH oxidase. Production of $\mathrm{O}_{2}^{-}$was calculated 1 and 2 min after starting the reaction with the addition of $\mathrm{NADPH}$ and was expressed as the amount of nmol of $\mathrm{O}_{2}{ }^{-}$ produced per $\mathrm{mg}$ of membrane protein (Figs. 2 and 3 ). No 


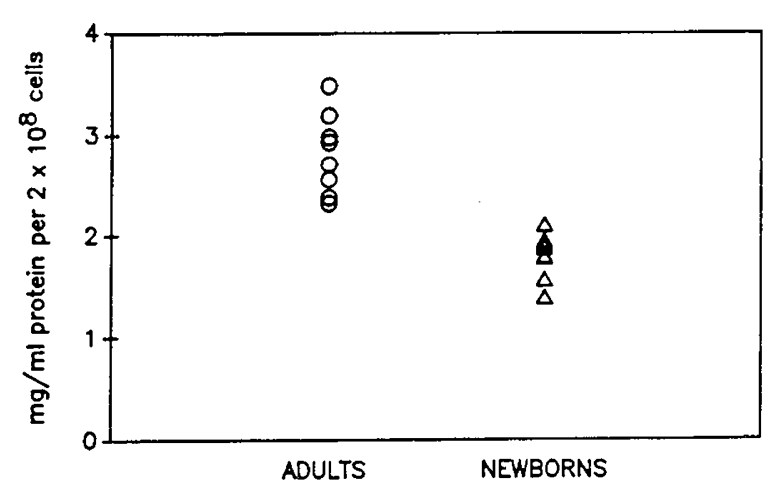

Fig. 1. Protein content in the membrane preparations resulting from the disruption of $2 \times 10^{8}$ neutrophils from adult cows $(n=8)$ and newborn calves $(n=9)$.

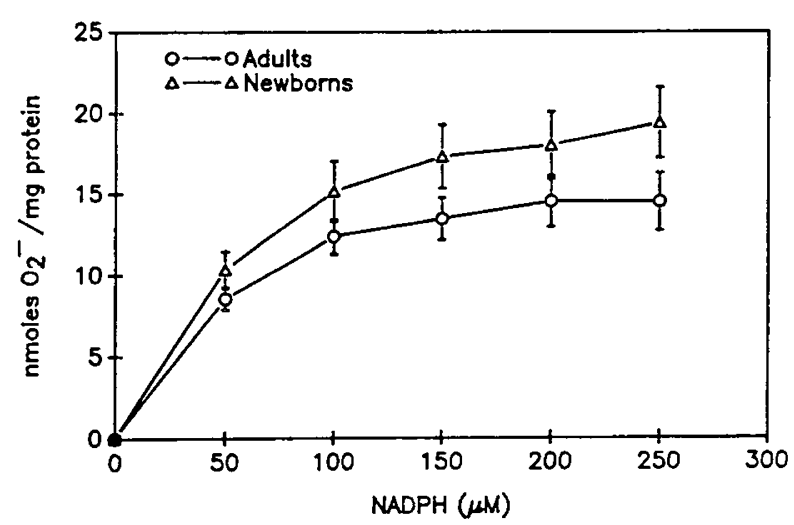

Fig. 2. $\mathrm{O}_{2}^{-}$production by PMA-stimulated membrane fractions of bovine adult and newborn neutrophils $1 \mathrm{~min}$ after starting the reaction by adding NADPH. Data represent the mean \pm SEM from eight separate experiments for adults and nine experiments for newborns, run in duplicate.

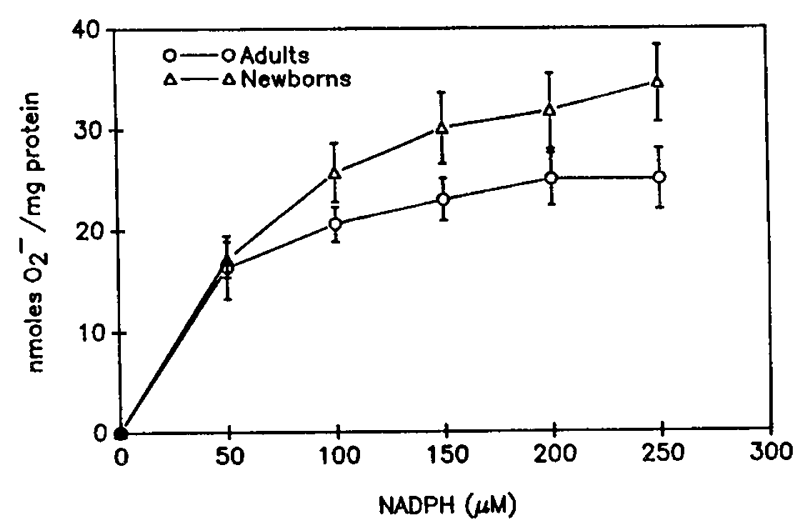

Fig. 3. $\mathrm{O}_{2}^{-}$production by PMA-stimulated membrane fractions of bovine adult and newborn neutrophils $2 \mathrm{~min}$ after starting the reaction by adding NADPH. Data represent the mean \pm SEM from eight separate experiments for adults and nine experiments for newborns, run in duplicate.

generation of $\mathrm{O}_{2}^{-}$was observed with preparations of membranes isolated from unstimulated cells (data not shown). At all concentrations of NADPH tested, there were no significant differences in the amount of $\mathrm{O}_{2}^{-}$produced by membranes of PMN from newborn calves and adult cows stimulated with PMA. Also, when production of $\mathrm{O}_{2}^{-}$was calculated per $1 \times 10^{7}$ cells, no significant differences were observed between the two groups (data not shown).

Kinetic parameters of the reaction. The $\mathrm{Km}$ and the $\mathrm{V}_{\max }$ of the reaction were calculated to compare the enzyme kinetics in newborn and adult PMN. No significant differences were present in the $\mathrm{Km}$ of the enzyme in PMN membranes of newborn calves and adult cows or in the $V_{\max }$ of the reaction in newborn and adult PMN (Table 1). We also estimated the velocity of the reaction according to the equation previously reported by Ambruso et al. (21) for human PMN where the calculated rate of $\mathrm{O}_{2}^{-}$production is based on measured kinetic parameters and on an estimated intracellular concentration of NADPH of $90 \mu \mathrm{M}$. According to this equation, membrane fractions from newborn calves produced $\mathrm{O}_{2}^{-}$at a similar rate to membranes isolated from PMN of adult animals (Table 1).

Determination of cell size. The diameters of newborn and adult PMN were estimated using flow cytometry by measuring the log forward angle light scattered of both populations of cells. The average diameter of live PMN from newborn calves $(10.94$ $\pm 0.07 \mu \mathrm{m})$ was significantly smaller $(p<0.01)$ than the diameter of PMN from adult cows $(11.65 \pm 0.06 \mu \mathrm{m})$. The same observation was made with fixed PMN analyzed the day of the experiment and with fixed samples that were saved and analyzed on the same day (Table 2). Calculated volume and surface area of live PMN were also significantly smaller in PMN from newborn calves compared with adult cows (Table 2).

\section{DISCUSSION}

Oxidative metabolism is an important component of the microbicidal activity of PMN. Abnormalities of the respiratory burst of PMN from human neonates have been described (1014), but their physiologic significance is still unclear and their biochemical basis poorly understood. Several reports have indicated that PMN from newborn infants produce significantly more $\mathrm{O}_{2}{ }^{-}$than control PMN from healthy adults when stimulated with PMA $(10,13)$ or with opsonized zymosan $(11,14)$. In accord with data obtained from whole PMN $(11,14)$, significantly increased production of $\mathrm{O}_{2}^{-}$by membranes from newborn $\mathrm{PMN}$ and a higher $\mathrm{V}_{\max }$ and apparent $\mathrm{Km}$ of their oxidase system consistent with a $30 \%$ greater rate of $\mathrm{O}_{2}{ }^{-}$production by newborn PMN have also been reported (21).

In the bovine species, the opposite phenomenon has been observed. Newborn bovine PMN generate significantly reduced amounts of $\mathrm{O}_{2}^{-}$compared with adult PMN when stimulated with the phorbol esters or with the synthetic diacylglycerol analogue 1,2-dioctanoyl-sn-glycerol (17-19). This impaired $\mathrm{O}_{2}^{-}$response of newborn calf PMN may be due to abnormalities at any one of several levels of the activation and signal transduction process. The exact biochemical events leading to activation of the respiratory burst enzyme in PMN have not yet been fully characterized, and may be stimulus-specific. With phorbol esters, it has been shown that activation of PKC is tightly involved in the activation of NADPH oxidase (28-30). Intermediary steps believed to play an important role include the phosphorylation of a group of $47-$ to $49-\mathrm{kD}$ proteins that are notably absent in PMN of patients with chronic granulomatous disease $(31-33)$.

Possible explanations for the age-related difference observed in the bovine species might include deficient or abnormal activity of the PKC system of newborn PMN, defective phosphorylation of their intermediate proteins, or abnormality or deficiency of the enzyme NADPH oxidase itself. External influences from the blood microenvironment must also be considered because the $\mathrm{O}_{2}{ }^{-}$deficit present in newborn calves represents a perinatal phenomenon; PMN isolated from late term bovine fetuses did not show a similar deficit (18). It must also be noted that newborn calves exhibit a significant neutrophilic leukocytosis in the first few hours after birth, probably due to high levels of corticosteroids in the circulation (26). It is therefore likely that the maturation stage of these PMN newly released from the bone marrow is somewhat different from circulating PMN of adult cows.

Our present study revealed no differences in the distal portion of the activation pathway of the enzyme NADPH oxidase. On a protein basis, membrane fractions from PMA-stimulated new- 
Table 1. Kinetic parameters of NADPH oxidase from bovine neutrophils

\begin{tabular}{|c|c|c|c|}
\hline & $\begin{array}{c}\mathrm{Km} \\
(\mu \mathrm{M} \mathrm{NADPH})\end{array}$ & $\begin{array}{c}\mathrm{V}_{\max } \\
\left(\mathrm{nmol} \mathrm{O} \mathrm{O}_{2} / \mathrm{min} / \mathrm{mg} \text { protein }\right)\end{array}$ & $\begin{array}{l}\text { Calculated velocity* } \\
(\mathrm{nmol} \mathrm{O}-2 / \mathrm{min} / \mathrm{mg})\end{array}$ \\
\hline Adults $(n=8)$ & $54.20 \pm 11.20$ & $18.53 \pm 2.54$ & $11.38 \pm 0.99$ \\
\hline Newborns $(n=9)$ & $66.18 \pm 5.50$ & $24.53 \pm 2.77$ & $14.15 \pm 1.63$ \\
\hline
\end{tabular}

* Velocity calculated using mean values for $\mathrm{Km}$ and $\mathrm{V}_{\max }$ and the equation $\mathrm{V}=\mathrm{V}_{\max }[\mathrm{NADPH}] / \mathrm{Km}+[\mathrm{NADPH}]$ (ref. 21).

Table 2. Morphometric parameters of bovine neutrophils measured by flow cytometry

\begin{tabular}{|c|c|c|}
\hline & $\begin{array}{c}\text { Adults } \\
(n=12)\end{array}$ & $\begin{array}{c}\text { Newborns } \\
(n=12)\end{array}$ \\
\hline \multicolumn{3}{|l|}{ Diameter $(\mu \mathrm{m})$} \\
\hline Live cells & $11.65 \pm 0.06$ & $10.94 \pm 0.07^{*}$ \\
\hline Fixed cells & $11.62 \pm 0.04$ & $11.24 \pm 0.02^{*}$ \\
\hline $\begin{array}{l}\text { Fixed cells ana- } \\
\text { lyzed on the } \\
\text { same day }\end{array}$ & $11.49 \pm 0.05$ & $11.20 \pm 0.07^{*}$ \\
\hline Volume $\left(\mu \mathrm{m}^{3}\right) \dagger$ & $829.40 \pm 13.20$ & $685.50 \pm 12.60^{*}$ \\
\hline Surface area $\left(\mu \mathrm{m}^{2}\right) \dagger$ & $426.76 \pm 4.53$ & $333.29 \pm 4.69^{*}$ \\
\hline
\end{tabular}

* Significantly different from adult neutrophils, $p<0.01$.

$\dagger$ Calculated using the diameter of live cells.

born PMN produced as much $\mathrm{O}_{2}^{-}$as did membranes isolated from adult PMN. The kinetics of the reaction were also similar in both age groups, as no differences were seen in either the $\mathrm{Km}$ or the $\mathrm{V}_{\max }$ of the reaction. The calculated $\mathrm{Km}$ of adult and newborn oxidases (54.20 and $66.18 \mu \mathrm{M}$, respectively) were also both inferior to $90 \mu \mathrm{M}$, which is the estimated intracellular concentration of NADPH previously reported for human PMN $(21,34)$, indicating that the oxidase is probably saturated in adult and newborn PMN. It therefore appears that the activity and kinetics of the enzyme NADPH oxidase of bovine newborn PMN is not different from the enzyme of adult cells. It could also be hypothesized that PMN from newborn calves have deficient intracellular supplies of NADPH. If the intracellular concentration of NADPH was less than the Km of the enzymatic reaction, NADPH oxidase would work at a suboptimal rate in intact cells. Qualitative or quantitative differences in the activity of the PKC system could also exist between adult and newborn PMN, inasmuch as decreased $\mathrm{O}_{2}{ }^{-}$generation by newborn bovine PMN has been observed with direct PKC agonists.

The reduced production of $\mathrm{O}_{2}^{-}$by newborn calf PMN (1719) might be understood if intact PMN from newborn calves possessed less total enzyme than adult PMN. Berkow and Baehner (22) have reported that circulating human PMN were heterogenous with respect to size, and that increased size correlated with increased oxidative burst and granule contents. It has also been shown that cell sonicates derived from the larger PMN fractions contained significantly more total cellular NADPHdependent oxidase activity than did smaller PMN fractions (23). Our data would support the hypothesis that a similar heterogeneity in size and NADPH oxidase activity in circulating PMN exists between newborn and adult bovine PMN. Differences in cell size between human newborn and adult PMN have not been reported, but Anderson et al. (7) reported morphometric evaluations of human newborn and adult PMN membrane perimeters, revealing that both resting and formyl-methionyl-leucyl-phenylalanine-activated neonatal PMN exposed significantly less plasma membrane than did their adult counterparts.

The consistently inferior protein content noted in membrane preparations from PMN of newborn calves indicated a possible size difference between adult and newborn bovine PMN. The cell diameter of adult and newborn PMN estimated by flow cytometry in this study were in the range of cell size previously reported for bovine PMN (25). Determination of cell size revealed that PMN from newborn calves had a significantly smaller diameter and therefore also a significantly smaller calculated volume and surface area than did PMN from adult cows. The surface area is probably the most important parameter, as it may be correlated with differences in the amount of plasma membrane and, by inference, quantity of enzyme. PMN from newborn calves had an average of $22 \%$ less calculated surface area than adult PMN. In keeping with published human data (22, 23), it is possible that the observed difference in cell size between newborn and adult bovine PMN would be reflected by a difference in their oxidative metabolism. The observed $22 \%$ difference in PMN size, however, can probably not fully account for the $41-49 \%$ difference in $\mathrm{O}_{2}^{-}$generation noted between newborn and adult bovine PMN (19).

Comparisons of the forward angle light scattered by live and fixed cells also revealed that fixation in $2.5 \%$ glutaraldehyde influenced this parameter. The difference observed was probably due to changes in membrane permeability related to fixation and to a consequent modification of the refractile index of the cells. To avoid such artefactual changes, all calculations of cell volume and surface area were made using the diameters obtained with live PMN.

A reduced production of $\mathrm{O}_{2}^{-}$as observed in PMN of newborn calves can potentially contribute to impairing their microbicidal activity and therefore help to explain the increased susceptibility to infections of neonates. Alternatively, one can also speculate that a diminished respiratory burst in newborn calves represents a protective mechanism to prevent PMN-induced tissue injury inasmuch as newborn calves are born in an environment where opportunities for bacterial infections are numerous.

Our study showed that the activity and kinetic parameters of the enzyme NADPH oxidase do not differ between adult and newborn bovine PMN, and that PMN size differences between the two age groups exist that could play a role in altered wholecell oxidative metabolism. Further studies will be needed to clarify the basis for the age-related difference in respiratory burst activation between newborn and adult bovine PMN.

Acknowledgments. The authors thank N. Pavlostky, Boston University School of Medicine, for technical advice on the NADPH oxidase assay, Dr. F. A. Kallfelz for use of the dualbeam spectrophotometer, Dr. A. J. Winter for the sonicator, and Dr. G. A. Weiland for the computer program used in the calculation of $\mathrm{Km}$ and $\mathrm{V}_{\max }$.

\section{REFERENCES}

1. Wilson CB 1986 Immunologic basis for increased susceptibility of the neonate to infection. J Pediatr 108:1-12

2. Hill HR 1987 Biochemical, structural, and functional abnormalities of polymorphonuclear leukocytes in the neonate. Pediatr Res 22:375-382

3. Banks KL 1982 Host defense in the newborn animal. J Am Vet Med Assoc 181:1053-1056

4. Anderson DC, Hughes BJ, Wible LJ, Perry GJ, Smith CW, Brinkley BR 1984 Impaired motility of neonatal PMN leukocytes: relationship to abnormalities of cell orientation and assembly of microtubules in chemotactic gradients. $\mathrm{J}$ Leukocyte Biol 36:1-15

5. Krause PJ, Kreutzer DL, Eisenfeld L, Herson VC, Weisman S, Bannon P, Greca N 1989 Characterization of nonmotile neutrophil subpopulations in neonates and adults. Pediatr Res 25:519-524

6. Boner A, Zeligs BJ, Bellanti JA 1982 Chemotactic responses of various differential stages of neutrophils from human cord and adult blood. Infect Immun 35:921-928

7. Anderson DC, Becker Freeman KL, Heerdt B, Hughes BJ, Jack RM, Smith CW 1987 Abnormal stimulated adherence of neonatal granulocytes: impaired induction of surface MAC-1 by chemotactic factors or secretagogues. Blood 70:740-750

8. Smith CW, Marlin SD, Anderson DC 1989 Impaired endothelial adhesion of neonatal neutrophils: abnormalities of MAC-1 (CD11b/CD18)-ICAM-1 adherence. Pediatr Res 26:1621(abstr) 
9. Olson TA, Ruymann FB, Cook BA, Burgess DP, Henson SA, Thomas PJ 1983 Newborn polymorphonuclear leukocyte aggregation: a study of physical properties and ultrastructure using chemotactic peptides. Pediatr Res 17:993-997

10. Strauss RG, Synder EL 1983 Activation and activity of the superoxidegenerating system of neutrophils from human infants. Pediatr Res 17:662664

11. Ambruso DR, Bentwood B, Henson PM, Johnston Jr RB 1984 Oxidative metabolism of cord blood neutrophils: relationship to content and degranulation of cytoplasmic granules. Pediatr Res 18:1148-1153

12. Kugo M, Sano K, Uetani Y, Nakamura H 1989 Superoxide dismutase in polymorphonuclear leukocytes of term newborn infants and very low birth weight infants. Pediatr Res 26:227-231

13. Yamazaki M, Matsuoka T, Yasui K, Komiyama A, Akabane T 1988 Increased production of superoxide anion by neonatal polymorphonuclear leukocytes stimulated with a chemotactic peptide. Am J Hematol 27:169-173

14. Ambruso DR, Altenburger KM, Johnston Jr RB 1979 Defective oxidative metabolism in newborn neutrophils: discrepancy between superoxide anion and hydroxyl radical generation. Pediatrics 64(suppl):722-725

15. Bryson DG, McFerran JB, Ball HJ, Neill SD 1978 Observations on outbreaks of respiratory disease in housed calves. 1. Epidemiological, clinical and microbiological findings. Vet Rec 103:485-489

16. Fleming $S 1985$ Enterotoxemia in neonatal calves. Vet Clin North Am [Food Anim Pract] 1:509-516

17. Holden W, Slauson DO, Zwahlen RD, Suyemoto MM, Doré M, Neilsen NR 1989 Alterations in complement-induced shape change and stimulusspecific superoxide anion generation by neonatal calf neutrophils. Inflammation 13:607-620

18. Clifford CB, Slauson DO, Neilsen NR, Suyemoto MM, Zwahlen RD, Schlafer DH 1989 Ontogeny of inflammatory cell responsiveness: superoxide anion generation by phorbol ester-stimulated fetal, neonatal, and adult bovine neutrophils. Inflammation 13:221-231

19. Doré M, Slauson DO, Neilsen NR 1990 Decreased respiratory burst activity in neonatal bovine neutrophils stimulated by protein kinase $\mathrm{C}$ agonists. Am $\mathrm{J}$ Vet Res (in press)

20. Babior BM 1988 The respiratory burst oxidase. Hematol Oncol Clin North Am 2:201-212

21. Ambruso DR, Stork LC, Gibson BE, Thurman GW 1987 Increased activity of the respiratory burst in cord blood neutrophils: kinetics of the NADPH oxidase enzyme system in subcellular fractions. Pediatr Res 21:205-210
22. Berkow RL, Baehner RL 1985 Volume-dependent human blood polymorphonuclear leukocyte heterogeneity demonstrated with counterflow centrifugal elutriation. Blood 65:71-78

23. Berkow RL, Dodson RW 1987 Volume dependent polymorphonuclear leukocyte fractions isolated by counterflow centrifugal elutriation: PMN volume does not correlate with PMN age. J Leukocyte Biol 41:518-526

24. Tauber AI 1985 Phagocyte NADPH-oxidase. In: Greenwald RA (ed) Handbook of Methods for Oxygen Radicals Research. CRC Press, Boca Raton, Florida, pp 25-30

25. Jain NC 1986 Cattle: normal hematology with comments on response to disease. In: Schalm's Veterinary Hematology, 4th Ed. Lea \& Febiger, Philadelphia, pp 185-187

26. LaMotte GB, Eberhart RJ 1976 Blood leukocytes, neutrophil phagocytosis, and plasma corticosteroids in colostrum-fed and colostrum-deprived calves. Am J Vet Res 37:1189-1193

27. Hudson S, Mullord M, Whittlestone WG, Payne E 1976 Plasma corticoid levels in healthy and diarrheic calves from birth to 20 days of age. $\mathrm{Br}$ Vet $\mathrm{J}$ 132:551-556

28. Wolfson M, McPhail LC, Nasrallah VN, Snyderman R 1985 Phorbol myristate acetate mediates redistribution of protein kinase $C$ in human neutrophils: potential role in the activation of the respiratory burst enzyme. J Immunol 135:2057-2062

29. Nishihira J, O'Flaherty JT 1985 Phorbol myristate acetate receptors in human polymorphonuclear neutrophils. J Immunol 135:3439-3447

30. Tauber AI 1987 Protein kinase $C$ and the activation of the human neutrophil NADPH-oxidase. Blood 69:711-720

31. Hayakawa T, Suzuki K, Suzuki S, Andrews PC, Babior BM 1986 A possible role for protein phosphorylation in the activation of the respiratory burst in human neutrophils. Evidence from studies with cells from patients with chronic granulomatous disease. J Biol Chem 261:9109-9115

32. Badwey JA, Heyworth PG, Karnovsky ML 1989 Phosphorylation of both 47 and $49 \mathrm{kDa}$ proteins accompanies superoxide release by neutrophils. Biochem Biophys Res Commun 159:1029-1035

33. Babior BM 1988 Protein phosphorylation and the respiratory burst. Arch Biochem Biophys 264:361-367

34. Baehner RL, Johnston Jr RB, Nathan DG 1972 Comparative study of metabolic and biochemical characteristics of severely glucose-6-phosphate dehydrogenase-deficient polymorphonuclear leukocytes and leukocytes from children with chronic granulomatous disease. J Reticuloendothel Soc 12:150166 